\title{
Characterization of a novel soluble $c$-type cytochrome in a moxD mutant of Methylobacterium extorquens AM1
}

\author{
Darren J. Day, David N. Nunn and Christopher Anthony* \\ Biochemistry Department, University of Southampton, Southampton SO9 3TU, UK
}

(Received 29 June 1989; revised 4 August 1989; accepted 4 October 1989)

\begin{abstract}
Methylobacterium extorquens AM1 contains a novel $c$-type cytochrome, called cytochrome $c$-553, previously thought to be a precursor of the electron acceptor (cytochrome $c_{L}$ ) for methanol dehydrogenase. Its amino acid composition and serological characteristics show that it has no structural relationship to cytochrome $c_{\mathrm{L}}$. It usually comprises less than $5 \%$ of the total $c$-type cytochromes. In a moxD mutant, which contains neither methanol dehydrogenase nor cytochrome $c_{\mathrm{L}}$, it comprises $30 \%$ of the soluble cytochrome and it has been purified and characterized from that mutant. Cytochrome $c-553$ is large $\left(M_{\mathrm{r}} \mathbf{2 3 0 0 0}\right)$, acidic and monohaem, with a redox potential of $194 \mathrm{mV}$. It reacts rapidly and completely with CO but is not autoxidizable. It is not autoreducible, and it is not an electron acceptor from methanol dehydrogenase or methylamine dehydrogenase, nor an important electron donor to the oxidase. It is able to accept electrons from cytochrome $c_{\mathrm{L}}$ and to donate electrons to cytochrome $c_{\mathrm{H}}$. It is present in the soluble fraction (presumably periplasmic) and membrane fraction of wild-type bacteria during growth on a wide range of growth substrates, but its function in these bacteria or in the moxD mutant has not been determined.
\end{abstract}

\section{Introduction}

Methylobacterium extorquens AM1 is a pink facultative methylotroph, previously known as Pseudomonas AM1 or Methylobacterium AM1 (Anthony, 1982). It was recently classified and renamed, and shown to be similar to other pink facultative methylotrophs such as $M$. organophilum and $M$. zatmanii (Green \& Bousefield, 1982; Green et al., 1988). It oxidizes methanol by way of the periplasmic quinoprotein methanol dehydrogenase (MDH) which interacts directly with a specific cytochrome $c$ (called cytochrome $c_{\mathrm{L}}$ ). This then transfers electrons to a typical small cytochrome $c$ (called cytochrome $c_{\mathrm{H}}$ ) which is the substrate for the membranebound oxidase cytochrome $a a_{3}$ (for reviews see Anthony, $1982,1986,1988)$. In the first extensive study of the genes involved in methanol oxidation, 10 gene functions were described in $M$. extorquens (Nunn \& Lindstrom, 1986a, $b$ ), including the structural gene for cytochrome $c_{\mathrm{L}}$ $(\operatorname{mox} G)$ which has been recently sequenced. The deduced protein structure showed that cytochrome $c_{\mathrm{L}}$ constitutes a completely novel class of $c$-type cytochrome (Nunn \& Anthony, 1988). It was also shown that it has a typical Nterminal signal peptide. A second mutation affecting the $c$-type cytochromes is at the moxD locus; this mutation

Abbreviation: MDH, methanol dehydrogenase. leads to production of an altered cytochrome $c$ which, it has been suggested (Nunn \& Lidstrom, 1986b), might represent cytochrome $c_{\mathrm{L}}$ with its signal peptide still attached.

The present paper investigates this possibility and concludes that the cytochrome observed in the moxD mutant is not related to cytochrome $c_{\mathrm{L}}$, but that it is a novel cytochrome which is always present in wild-type $M$. extorquens but which usually comprises less than $5 \%$ of the soluble cytochrome $c$. In moxD mutants it is produced in high concentrations, in the absence of either the normal cytochrome $c_{L}$ or $\mathrm{MDH}$.

\section{Methods}

Bacterial strains, growth and disruption of bacteria. Methylobacterium extorquens (NCIB 9133), previously known as Pseudomonas AM1 or Methylobacterium AM1 (Green et al., 1988), was grown at $30^{\circ} \mathrm{C}$ on the medium of MacLennan et al. (1971) as described by O'Keeffe \& Anthony $(1980 b)$, with methanol $(0.5 \%)$ as carbon source unless otherwise stated. The moxD mutant (UV9), described by Nunn \& Lidstrom $(1988 a, b)$, was grown on the same medium as the wild-type strain except that the carbon source was $0.5 \%$ methylamine. It was grown in a 20 litre fermentor, harvested at the end of the exponential phase by centrifugation, and washed and resuspended in $20 \mathrm{~mm}$ Tris/ $\mathrm{HCl}(\mathrm{pH} \mathrm{8.0)}$. A suspension of $120 \mathrm{~g}$ wet wt in $900 \mathrm{ml}$ was disrupted by sonication in $50 \mathrm{ml}$ batches using an MSE Soniprep ultrasonic disintegrator at full power for $6 \mathrm{~min}$ (in cycles of $30 \mathrm{~s}$ on and 
$30 \mathrm{~s}$ off ) with cooling in an ice/salt bath. Cell debris and unbroken cells were removed by centrifugation for $10 \mathrm{~min}$ at $10000 \mathrm{~g}$. The supernatant liquid was decanted and centrifuged to remove membranes at $120000 \mathrm{~g}$ for $90 \mathrm{~min}$ to provide crude soluble extract. The membranes were washed once in $20 \mathrm{mM}-\mathrm{MOPS} / \mathrm{NaOH}$ buffer $(\mathrm{pH} \mathrm{7.0)}$ and resuspended in the same buffer.

Purification of cytochrome c-553. The crude soluble extract was applied to a column of DEAE-Sephacel (Pharmacia) (45 mm diameter, $75 \mathrm{~mm}$ length) equilibrated in $20 \mathrm{~mm}-\mathrm{Tris} / \mathrm{HCl}$ buffer (pH 8.0). The column was then washed with 5 column vols of the same buffer at a flow-rate of $3 \mathrm{ml} \mathrm{min}-1$. This eluted the cytochrome $c_{\mathrm{H}}$. Cytochrome $c-553$ was eluted with $250 \mathrm{~mm}-\mathrm{NaCl}$ in the same Tris buffer, the salt removed by dialysis against the same buffer and the cytochrome applied to a column ( $95 \mathrm{~mm} \times 25 \mathrm{~mm}$ diameter) of DEAE-Sepharose (Fast-Flow; Pharmacia). The column was washed with $100 \mathrm{~mm}-\mathrm{NaCl}$ and the cytochrome eluted with $150 \mathrm{mM}-\mathrm{NaCl}$ in the same Tris buffer. It was taken to $45 \%$ saturation with ammonium sulphate at $4{ }^{\circ} \mathrm{C}$ and the precipitate removed by centrifugation $(3000 \mathrm{~g}$ for $15 \mathrm{~min})$. The supernatant liquid, containing the cytochrome, was applied to a column of phenyl Superose (Pharmacia HR 5/5 column) equilibrated with $1.8 \mathrm{M}$-ammonium sulphate in $20 \mathrm{~mm}$-MOPS buffer (final pH 7.0). The column was washed with $1 \mathrm{M}$-ammonium sulphate in the same buffer before eluting the cytochrome with $0.8 \mathrm{M}$-ammonium sulphate in the same buffer. Final purification was achieved by gel-filtration on a Superose-12 column (Pharmacia) equilibrated with $50 \mathrm{~mm}-\mathrm{Tris} / \mathrm{HCl}$ containing $100 \mathrm{mM}-\mathrm{NaCl}(\mathrm{pH} 8.0)$ at a flow rate of $0.5 \mathrm{ml} \mathrm{min}{ }^{-1}$. For estimation of relative molecular mass by gel-filtration the same column was used with the following standards $\left(M_{\mathrm{r}}\right.$ values in parentheses): apoferritin (443000); ovalbumin (44000); haemoglobin (64000); myoglobin (17000); horse heart cytochrome $c(12400)$; and vitamin $B_{12}$ (1350).

Determination of proportions of cytochromes $c-553, c_{\mathrm{H}}$ and $c_{\mathrm{L}}$. Crude soluble extracts $(100 \mu \mathrm{l}$ containing $1 \mathrm{mg}$ protein) were applied to a Pharmacia Mono-Q column ( $1 \mathrm{ml})$ equilibrated with $20 \mathrm{mM}-\mathrm{Tris} / \mathrm{HCl}$ buffer ( $\mathrm{pH} \mathrm{8.0)}$. The column was washed with $5 \mathrm{ml}$ of the same buffer in order to wash-out the cytochrome $c_{\mathrm{H}}$ and cytochromes $c-553$ or $c_{\mathrm{L}}$ were eluted with a linear gradient $(0-180 \mathrm{~mm}-\mathrm{NaCl}$; total vol. $12 \mathrm{ml})$. The acidic cytochromes eluted between 100 and $120 \mathrm{~mm}-\mathrm{NaCl}$. The concentration of cytochromes was determined using the absorption coefficients of the cytochromes (Table 1, and O'Keeffe \& Anthony, $1980 a$ ).

Protein and haem determination. Protein was measured as described by Smith et al. (1988) using the bicinchoninic acid method with horse heart cytochrome $c$ as standard. Haem was determined as the pyridine haemochrome as described by Fuhrhop \& Smith (1975).

Spectrophotometry. Absorption spectra were recorded using a Shimadzu UV-3000. A few grains of dithionite or ascorbic acid were added to reduce the samples and a few grains of ferricyanide or ammonium persulphate to oxidize the samples. All spectra were run at $100 \mathrm{~nm} \mathrm{~min}^{-1}$ (spectral bandwidth $1 \mathrm{~nm}$ ). For spectra in the near-infrared region the sum of 16 accumulated spectra $(0 \cdot 1 \mathrm{~nm}$ sampling pitch) was recorded.

Redox potentials. These were measured by the method of O'Keeffe \& Anthony (1980a) except that the concentration of cytochrome $c-553$ was $1.7 \mu \mathrm{M}$ and the following mediators were used: diaminodurol $(75 \mu \mathrm{M})$, hydroquinone $(50 \mu \mathrm{M})$, pyocyanin $(7.5 \mu \mathrm{M})$ and potassium ferricyanide $(75 \mu \mathrm{M})$. All solutions were in $20 \mathrm{mM}$-MOPS buffer ( $\mathrm{pH} 7 \cdot 0$ ) containing $100 \mathrm{~mm}-\mathrm{KCl}$.

Antisera preparation and Western blotting. Purified cytochrome c-553 or cytochrome $c_{\mathrm{L}}(400 \mu \mathrm{g})$ was suspended in Freund's complete adjuvent and used to immunize two New Zealand White rabbits; two boosters of cytochrome ( $100 \mu \mathrm{g}$ each) were given at 1 month intervals. Blood was collected (from the ear) and an IgG fraction prepared from the serum by ammonium sulphate fractionation as described by Hudson \& Hay (1980). After SDS-PAGE, Western blotting was done essentially as described by Gershoni \& Palade (1983); the electrophoretic transfer buffer was $25 \mathrm{mM}$-Tris/192 mM-glycine (pH 8.3) containing $20 \%(\mathrm{w} / \mathrm{v})$ methanol. Blocking was done with a $5 \%(\mathrm{w} / \mathrm{v})$ solution of non-fat dried milk in Tris-buffered saline $(50 \mathrm{~mm}$-Tris/ $\mathrm{HCl}$ containing $100 \mathrm{~mm}-\mathrm{NaCl}$ ). Bound antibodies were detected by horse-radish peroxidase conjugated to rabbit anti-IgG.

Preparation of proteins from Methylophilus methylotrophus, organism 4025, Paracoccus denitrificans and Acetobacter methanolicus. Methods for growth and preparation of cell fractions and purified proteins were exactly as described previously: $M$. methylotrophus (Cross \& Anthony, 1980); organism 4025 (Lawton \& Anthony, 1985); P. denitrificans (Beardmore-Gray et al., 1983); A. methanolicus (Elliott \& Anthony, 1988).

$S D S-P A G E$. The SDS-Tris/glycine pH 8.3 system (Laemmli, 1970) was used and protein bands were stained with Coomassie Brilliant Blue R250, as described by Weber \& Osborn (1975). Final acrylamide concentrations $(\mathrm{w} / \mathrm{v})$ of $10 \%$ (for whole cells and membranes) or $15 \%$ (for soluble fractions) were used. When whole bacteria were used they were boiled for $10 \mathrm{~min}$ in disruption buffer and insoluble debris removed by centrifugation. Gels were stained for haem proteins with 3,3',5,5'-tetramethylbenzidine (TMBZ) by the method of Thomas $e t$ al. (1976), and haem $c$ was detected specifically as described by Goodhew et al. (1986). Samples that were to be haem-stained were mixed with disruption buffer lacking mercaptoethanol because heating in its presence caused loss of haem iron and a decrease in staining intensity. $M_{\mathrm{r}}$ values and proportions of each protein in electrophoresed samples were determined as described by Elliott \& Anthony (1988).

Autoreduction and reaction with dehydrogenases. Cytochrome was reduced with ascorbic acid or oxidized with ferricyanide, the excess being removed by gel-filtration on a PD-10 column (Pharmacia). Oxidation or reduction reactions were determined by monitoring changes in absorption of the $\alpha$ absorption maximum of each cytochrome. Autoreduction in the presence or absence of methanol dehydrogenase (MDH), and reduction of cytochrome $c$ by MDH was determined as described previously (O'Keeffe \& Anthony, 1980 $a$; Beardmore-Gray et al., 1983). The MDH was prepared from $M$. extorquens as described by Nunn et al. (1989); cytochrome $c_{\mathrm{H}}$ was prepared as described by O'Keeffe \& Anthony (1980a) and cytochrome $c_{\mathrm{L}}$ was prepared as described by Nunn \& Anthony (1988). The concentration of $\mathrm{MDH}$ was about $0 \cdot 3 \mu \mathrm{M}$, which was sufficient to reduce rapidly cytochrome $c_{\mathrm{L}}(30 \mu \mathrm{M})$. Reactions were in $400 \mu \mathrm{l}$ cuvettes in $20 \mathrm{~mm}$-MOPS buffer ( $\mathrm{pH} 7 \cdot 0$ ) containing $5 \mathrm{~mm}$-methanol and $13 \mathrm{~mm}$-ammonium chloride. A similar assay was used for testing reaction with methylamine dehydrogenase. The reaction was in $1 \mathrm{ml}$ cuvettes in $20 \mathrm{mM}-\mathrm{MOPS}$ buffer (pH 7.0) containing $25 \mathrm{mM}$-methylamine, $26 \mu \mathrm{M}$-cytochrome $c$-553 and about $0 \cdot 3 \mu \mathrm{M}$-methylamine dehydrogenase, prepared and assayed as previously described (Lawton \& Anthony, 1985); its specific activity was $3.5 \mu \mathrm{mol} \mathrm{min}^{-1}(\mathrm{mg} \text { protein })^{-1}$ in the standard dye-linked assay.

Oxidation of cytochromes by membranes. This was measured spectrophotometrically using $10 \mu \mathrm{l}$ of membrane suspension $\left(0.2 \mathrm{mg} \mathrm{ml}^{-1}\right)$ in $20 \mathrm{~mm}-\mathrm{MOPS}, \mathrm{pH} 7.0$, in a $400 \mu \mathrm{l}$ cuvette. Cytochromes were reduced by a grain of ascorbate followed by rapid desalting by gel-filtration on a Pharmacia PD10 column. A range of cytochrome $c$ concentrations was used so that values for $V$ (maximal velocity) could be determined. 


\section{Results}

Replacement of cytochrome $c_{L}$ by cytochrome $c-553$ in the moxD mutant (UV9)

The moxD mutant (UV9), grown on methylamine, contained no cytochrome $c_{\mathrm{L}}$, as shown by Western blots of SDS extracts of whole bacteria, and of membrane and soluble fractions after breakage by sonication. The spectrum of the membrane fraction of mutant UV9 was slightly different from that in wild-type bacteria (Fig. 1). The proportions of cytochromes $a, b$ and $c$ were similar to those in wild-type bacteria but the $\alpha$ absorption peak of cytochrome $c$ was slightly higher, suggesting that the cytochrome $c_{\mathrm{L}}$ observed in membranes of wild-type bacteria might be replaced by cytochrome $c-553$ in the mutant. This was confirmed by Western blot analysis of SDS extracts of membranes using antibodies to cytochromes $c_{\mathrm{L}}$ and $c$-553. It is not possible to say whether or not this implies any function for these membrane-bound cytochromes in $M$. extorquens. The soluble fraction of mutant UV9 (which, of course, contains the periplasm) had two $c$-type cytochromes which could be separated by ion-exchange chromatography on DEAE-Sephacel; one had a high isoelectric point (not adsorbing to DEAESephacel) and was indistinguishable from cytochrome $c_{\mathrm{H}}$; the other adsorbed to the column, suggesting a low isoelectric point. This acidic cytochrome had an $\alpha$ peak at $553 \mathrm{~nm}$ instead of $550 \mathrm{~nm}$ as expected for cytochrome $c_{\mathrm{L}}$, and hence is called cytochrome $c$-553 in the rest of this paper. The amount of cytochrome $c_{\mathrm{H}}$ in soluble fractions was very similar to that in wild-type bacteria and the amount of cytochrome $c-553$ was similar to that of cytochrome $c_{\mathrm{L}}$ in wild-type bacteria. Because of the presence of large amounts of cytochrome $c-553$, the absorbance maximum of crude soluble fractions of mutant UV9 was at $552 \mathrm{~nm}$ rather than $550 \mathrm{~nm}$ as in wild-type bacteria.

In order to characterize further the novel cytochrome $c-553$ it was purified and characterized from the moxD mutant (UV9).

\section{Purification and characterization of cytochrome c-553}

Purification of cytochrome c-553. In order to compare it with cytochrome $c_{\mathrm{L}}$ from wild-type bacteria, the cytochrome $c-553$ was purified from mutant UV9 as described in Methods. The yield was about $15 \%$ and the purification achieved was about 25 -fold, based on mols cytochrome $c-553$ (g soluble protein) ${ }^{-1}$ (calculated by assuming that this cytochrome constituted $30 \%$ of the total soluble $c$-type cytochrome). The cytochrome $c$-553 was judged to be pure on the basis of its behaviour on SDS-PAGE (a single band when stained with Coomassie Blue and when haem-stained); it was the only protein

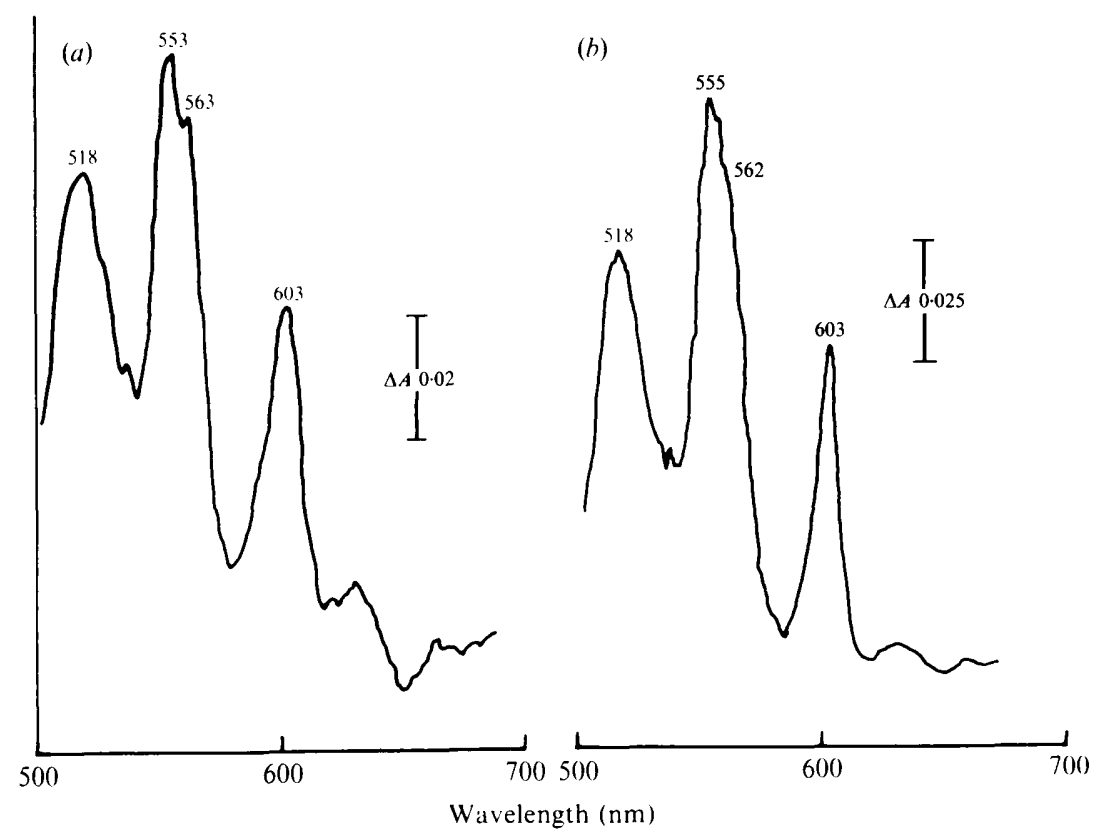

Fig. 1. Reduced-minus-oxidized difference spectra of membranes from wild-type and mutant bacteria at $77 \mathrm{~K}$. Membranes, in $25 \mathrm{mM}-$ HEPES/ $\mathrm{NaOH}$ buffer ( $\mathrm{pH} 7.5)$ containing $40 \%(\mathrm{w} / \mathrm{v})$ sucrose were reduced with dithionite and oxidized with ferricyanide. (a) Wildtype bacteria $\left(11.6 \mathrm{mg}\right.$ membrane protein $\left.\mathrm{ml}^{-1}\right) ;(b)$ mutant UV9 $\left(7.0 \mathrm{mg} \mathrm{ml}^{-1}\right)$. The light path was $1 \mathrm{~mm}$, the bandwidth was $1 \mathrm{~nm}$ and the scan speed was $100 \mathrm{~nm} \mathrm{~min}{ }^{-1}$. 
present as judged by its behaviour (single peak) on gelfiltration on Superose-12, and on ion-exchange chromatography on Pharmacia Mono-Q. On the basis of the purification achieved, the cytochrome comprised about $4 \%$ of the soluble protein of the bacteria. This is similar to the proportion calculated for the cytochrome $c_{\mathrm{L}}$ in wild-type bacteria.

$M_{\mathrm{r}}$, isoelectric point and midpoint redox potential of cytochrome $c-553$. The $M_{\mathrm{r}}$ was 23000 as determined by SDS-PAGE with $M_{\mathrm{r}}$ standards. This was the same as that estimated by gel-filtration on a calibrated Superose12 column (Pharmacia). The isoelectric point was judged to be low because of its behaviour on ion-exchange chromatography (binding to anion-exchange materials but not to cation-exchange materials). Cytochrome $c-553$ titrated as a single electron carrier with a midpoint redox potential at $\mathrm{pH} 7.0$ of $194 \mathrm{mV}$. Using the same equipment and method it was confirmed that the midpoint redox potential of cytochrome $c_{\mathrm{L}}$ was $256 \mathrm{mV}$ as shown previously by O'Keeffe \& Anthony (1980a).

Amino acid composition of cytochrome c-553. The amino acid composition of the cytochrome was determined as described previously (Beardmore-Gray et al., 1982). It is presented with the values for cytochrome $c_{\mathrm{L}}$ (from Beardmore-Gray et al., 1983) given for comparison in parentheses (ND, not determined): Asx, 23 (24); Thr, 4 (14); Ser 1 (7); Glx, 20 (26); Pro, 8 (13); Gly, 19 (23); Ala, 24 (14); Cys, ND (3); Val, 8 (5); Met, 3 (3); Ile, 4 (6); Leu, 11 (15); Tyr, 10 (6); Phe, 5 (5); His, 8 (7); Lys, 17 (13); Arg, 6 (4); Trp, ND (2). It is obvious from these values that cytochrome $c-553$ is not a derivative of cytochrome $c_{\mathrm{L}}$ (or vice versa). It was not possible to determine the $\mathrm{N}$-terminal amino acid sequence of cytochrome $c$-553 because it was shown to be blocked.

Absorption spectra of cytochrome c-553. Cytochrome $c-553$ was in the oxidized state when eluted from DEAESephacel; in this it differs from cytochromes $c_{\mathrm{H}}$ and $c_{\mathrm{L}}$ which are usually almost completely reduced when isolated. Reaction with alkaline pyridine gave a typical haem $c$ spectrum, with $1.06 \mathrm{~mol}$ haem (mol cytochrome) ${ }^{-1}$ (assuming $M_{\mathrm{r}}=23000$ ). This demonstrates that the cytochrome is a monohaem cytochrome $c$ and this is confirmed by its spectrum which is that of a typical low-spin c-type cytochrome (Fig. 2). The absorption band in the near-infrared region (about $695 \mathrm{~nm}$ ) shown by the cytochrome when oxidized by air, ferricyanide, ammonium persulphate or hydrogen peroxide (Fig. 2) is characteristic of $c$-cytochromes having methionine as their 6th ligand (Pettigrew \& Moore, 1987). The absorption peaks of cytochrome $c_{\mathrm{L}}$ and cytochrome $c-553$ (Fig. 3) are clearly distinguishable, being $550 \mathrm{~nm}$, $520 \mathrm{~nm}$ and $417 \mathrm{~nm}$ for cytochrome $c_{\mathrm{L}}$, and $553 \mathrm{~nm}, 523-$ $524 \mathrm{~nm}$ and $419 \mathrm{~nm}$ for cytochrome c-553.

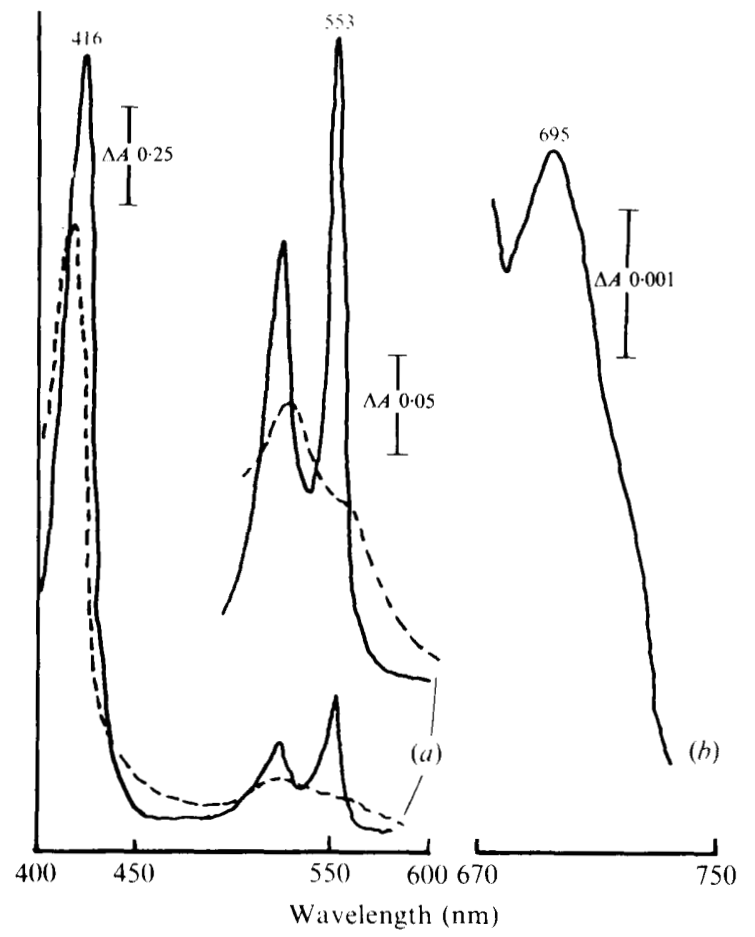

Fig. 2. Absorption spectra of cytochrome $c$-553. (a) Cytochrome $(9 \mu \mathrm{M}$, 20 mM-HEPES buffer, $\mathrm{pH} 7.5$ ) was reduced by addition of a few grains of dithionite, or oxidized by leaving in air at $2^{\circ} \mathrm{C}$ for $24 \mathrm{~h}$. (b) Oxidized cytochrome in the near-infrared region (accumulated spectrum as described in Methods).

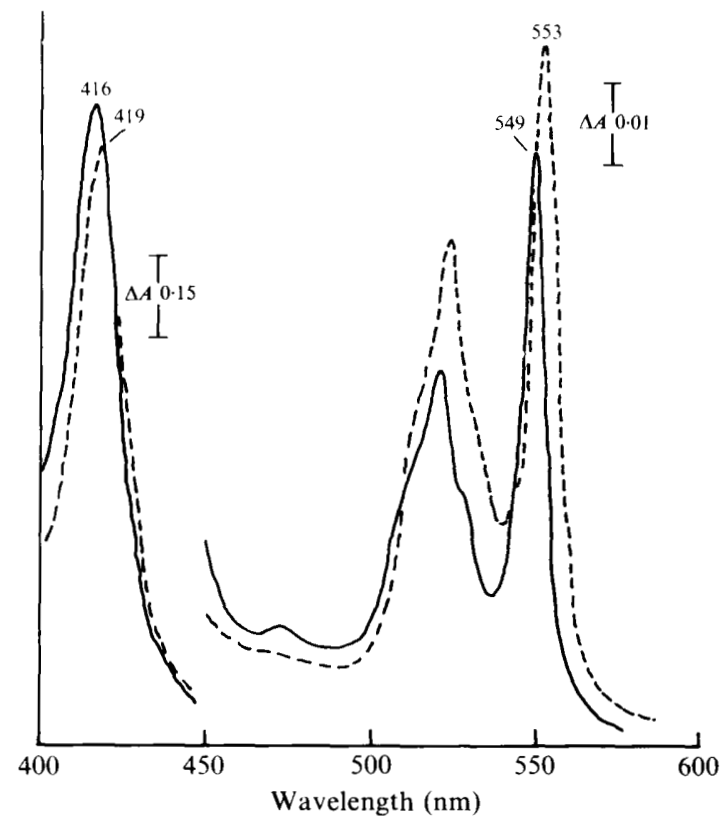

Fig. 3. Comparison of cytochromes $c-553$ and $c_{\mathrm{L}}$. The cytochromes were reduced with dithionite. - Cytochrome $c_{\mathrm{L}}(4.9 \mu \mathrm{M}) ;---$, cytochrome $c-553(6.9 \mu \mathrm{M})$. 


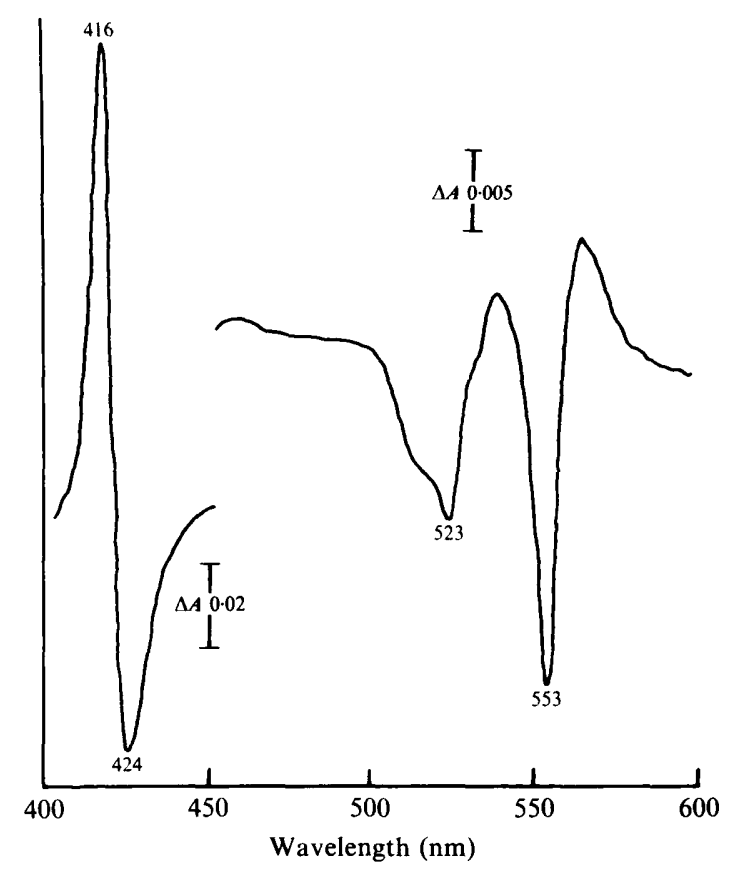

Fig. 4. The (reduced plus $\mathrm{CO}$ )-minus-reduced difference spectrum of cytochrome $c-553$. Cytochrome $(2.3 \mu \mathrm{M}$ in $20 \mathrm{mM}$-HEPES buffer, $\mathrm{pH} 7.5$ ) was reduced with a few grains of dithionite and $\mathrm{CO}$ was bubbled through a sample as a fine stream for $30 \mathrm{~s}$; its spectrum was recorded and $\mathrm{CO}$ passed through for a further $60 \mathrm{~s}$ and the spectrum recorded again.

Reaction with carbon monoxide and autoxidizability of cytochrome c-553. The spectrum shown in Fig. 4 shows that cytochrome $c-553$ reacted rapidly with $\mathrm{CO}$. When $\mathrm{CO}$ was bubbled through a solution for $30 \mathrm{~s}$ the spectrum indicated $81 \%$ binding to $\mathrm{CO}$, assuming the usual extinction coefficient for CO-reactive $c$-type cytochromes (Wood, 1984). After a further $60 \mathrm{~s}$ of bubbling the reaction was complete (this was after a total exposure time of about 4 min, including the time for running the spectra). This rapid and complete reaction with $\mathrm{CO}$ is markedly different from the reaction of cytochrome $c_{\mathrm{L}}$ of $M$. extorquens, which is well-known as a CO-reactive cytochrome and which has a slow partial reaction with $36 \%$ reaction after $5 \mathrm{~min}$ and $72 \%$ reaction after $30 \mathrm{~min}$ (O'Keeffe \& Anthony, 1980a).

When freshly reduced cytochrome was exposed to air it was slowly oxidized, the time taken for half-oxidation being about $2 \mathrm{~h}$.

\section{Electron transfer reactions of cytochrome c-553}

Autoreduction and reaction with methanol dehydrogenase and methylamine dehydrogenase. Key characteristics of cytochrome $c_{\mathrm{L}}$ are that it is autoreduced at high $\mathrm{pH}$ and that it is the electron acceptor for MDH. In the absence of methanol, addition of MDH to cytochrome $c_{\mathrm{L}}$ leads to its reduction either by stimulation of autoreduction or by transfer of electrons from endogenous reductant on the MDH (O'Keeffe \& Anthony, 1980 $a$; Beardmore-Gray et al., 1983). By contrast with cytochrome $c_{\mathrm{L}}$, cytochrome $c$-553 was not autoreduced (at $\mathrm{pH} 9.0$ ) and it showed no reaction with pure MDH from $M$. extorquens in the presence or absence of methanol. Possible reaction was assessed at $\mathrm{pH} 7$ or $\mathrm{pH} 9$ in the presence or absence of ammonia as activator, either with cytochrome $c-553$ as sole potential electron acceptor or with a second cytochrome $c$ as terminal acceptor, and in the presence or absence of air. The amounts of cytochrome and dehydrogenase used were such that a rate of $1 \%$ of that observed with $\mathrm{MDH}$ and cytochrome $c_{\mathrm{L}}$ would have been readily measured.

No reaction occurred in a similar system in which MDH was replaced by methylamine dehydrogenase.

Oxidation of cytochrome c-553 by the oxidase in membranes of $M$. extorquens. It has been shown previously that $M$. extorquens contains a single major oxidase, cytochrome $a a_{3}$, which has been purified and characterized (Fukumori et al., 1985; Fukumori \& Yamanaka, 1987). In the present work membranes prepared from wild-type bacteria catalysed the rapid, azide-sensitive oxidation of cytochrome $c_{\mathrm{H}}$ and horse heart cytochrome $c$ [ 49 and $28 \mathrm{nmol}$ cytochrome oxidized $\mathrm{min}^{-1}$ (mg membrane protein $)^{-1}$ respectively]. By contrast, the rate of oxidation of cytochrome $c-553$ was only $1.5 \mathrm{nmol} \mathrm{min}-1 \mathrm{mg}^{-1}$, a value similar to that

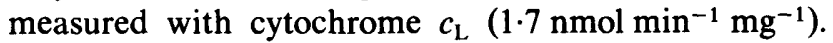
Cytochrome $c-553$ had no effect on the rate of oxidation of cytochrome $c_{\mathrm{H}}$ by the oxidase.

The $K_{\mathrm{m}}$ values for oxidation of all cytochromes tested were very similar to each other (about $7 \mu \mathrm{M}$ ) and similar to the $K_{\mathrm{m}}$ values measured for the oxidation of cytochrome $c_{\mathrm{H}}$ and $c_{\mathrm{L}}$ by the pure oxidase from M. extorquens (Fukumori et al., 1985; Fukumori \& Yamanaka, 1987). The oxidation rates (and $K_{\mathrm{m}}$ values) for the oxidation of cytochromes by membranes prepared from the mutant UV9 were almost identical to those measured with membranes from wild-type bacteria. All these results are consistent with the properties of the purified oxidase and indicate that the novel cytochrome $c-553$ does not function as an important electron donor to the oxidase, a function previously concluded to be that of cytochrome $c_{\mathrm{H}}$ (Fukumori et al., 1985; Fukumori \& Yamanaka, 1987; Froud \& Anthony, 1984).

Electron transfer between cytochromes c-553, $c_{\mathrm{H}}$ and $c_{\mathrm{L}}$. Using the membrane oxidase system described above, it was shown that the rate of oxidation of cytochrome $c-553$ $(31 \mu \mathrm{M})$ was increased 15 -fold by addition of $0.6 \mu \mathrm{M}$ cytochrome $c_{\mathrm{H}}$, and the cytochrome $c-553$ became 
completely oxidized. This confirms that rapid electron transfer can occur between cytochrome $c$-553 and cytochrome $c_{\mathrm{H}}$, the usual electron donor to the oxidase.

Using cytochrome $c$-553 as terminal electron acceptor in the $\mathrm{MDH} /$ cytochrome $c_{\mathrm{L}}$ system it was shown that rapid electron transfer could occur between cytochrome $c_{\mathrm{L}}$ and cytochrome $c-553$. When cytochrome $c-553$ was present in 8-fold excess over cytochrome $c_{\mathrm{L}}$ it became completely reduced by MDH although, as shown above, it was not itself an electron acceptor from MDH. The rate measured with both cytochromes together was the same as that when cytochrome $c_{\mathrm{L}}$ was the only cytochrome present.

\section{Serological characterization and distribution of the cytochrome}

Using Western blot analysis it was shown that antiserum raised to pure cytochrome $c$-553 reacted with the cytochrome but with no other cytochrome tested. These included the following: horse heart cytochrome $c$, cytochromes $c_{\mathrm{H}}$ and $c_{\mathrm{L}}$ of $\boldsymbol{M}$. extorquens, and cytochromes $c_{\mathrm{L}}$ from Methylophilus methylotrophus and organism 4025 (obligate methylotrophs), Acetobacter methanolicus (an acidophile) and Paracoccus denitrificans (a facultative autotroph). No cross-reaction was observed when using SDS extracts of whole cells, membranes or soluble fractions of any of these organisms (except for $M$. extorquens).

Antiserum raised to pure cytochrome $c_{\mathrm{L}}$ of $M$. extorquens failed to react with cytochromes $c-553$ or $c_{\mathrm{H}}$ of this organism or with cytochromes $c_{\mathrm{L}}$ from $M$. methylotrophus, organism 4025 or $P$. denitrificans. There was a weak reaction with the pure cytochrome $c_{\mathrm{L}}$ from $A$. methanolicus.

Western blot analysis was used to show that protein reacting with antiserum specific to cytochrome $c-553$ was present in large amounts in SDS-solubilized extracts of whole cells of mutant UV9, from which cytochrome $c$-553 was isolated, but in very much lower amounts (estimated to be less than $5 \%$ of that in the mutant) in extracts of wild-type $M$. extorquens after growth on methanol, methylamine, ethanol, propanediol, pyruvate, lactate, succinate and nutrient broth. There was no indication from these experiments that the cytochrome was induced to higher levels on any of these substrates; hence no suggestion of any specific function has arisen from this work.

\section{Discussion}

The results described above have demonstrated that the previous explanation of the moxD mutation (Nunn \&
Lidstrom, 1986b) was incorrect. It was suggested that this mutant might be lacking a processing function that explained three aspects of its phenotype: the lack of $\mathrm{MDH}$, lack of normal cytochrome $c_{\mathrm{L}}$ and the presence of a slightly larger, acidic cytochrome $c$. It was proposed that this cytochrome might be cytochrome $c_{\mathrm{L}}$ with its signal peptide still attached. That this is not the case is demonstrated by the lack of serological relationship between the two cytochromes, and the markedly different amino acid composition. The other differences in properties, listed in Table 1 , confirm the separate identity of the two cytochromes. This conclusion is supported by the genetic evidence: cytochrome $c-553$ is still synthesized in a mutant in which the gene for cytochrome $c_{\mathrm{L}}$ has been completely deleted (data not shown).

The conclusion that cytochrome $c-553$ is a completely different cytochrome raises the question of its nature and its function. It is a typical cytochrome $c$ in being a soluble (presumably periplasmic), monohaem cytochrome, having a high midpoint redox potential and methionine as its 6th ligand to the haem iron. It is unusual in its large size, its rapid and complete reaction with $\mathrm{CO}$ and its low rate of oxidation by the cytochrome $a a_{3}$ in membranes of $M$. extorquens.

The function of this cytochrome remains obscure. It is neither an electron acceptor for MDH or methylamine dehydrogenase nor an effective electron donor to the oxidase. It is present on all growth substrates but only at low concentrations.

The nature of the moxD mutation is very difficult to comprehend. An obvious possibility is that it is a regulatory mutant which inhibits expression of the operon coding for MDH and its electron acceptor, cytochrome $c_{\mathrm{L}}$. Why this mutation should lead to 'overproduction' of what is usually a very minor cytochrome of no known function remains, however, completely obscure. The possibility that cytochrome $c-553$ is induced to high levels in order to replace a function normally carried out by cytochrome $c_{\mathrm{L}}$, but not specifically involved in methanol oxidation, cannot be discounted.

It should be noted that cytochrome $c-553$ of $M$. extorquens bears only a superficial resemblance to $c$-type cytochromes having absorption maxima above $552 \mathrm{~nm}$ that have been isolated from other methylotrophs. These include cytochrome $c$ (IV) of Hyphomicrobium ZV580 which is, however, almost certainly the electron acceptor for MDH (cited by Dijkstra et al., 1988). More similar is cytochrome $c$-553i from $P$. denitrificans, which is, however, also involved in methanol oxidation and is also much larger than the cytochrome $c-553$ described in the present paper (Husain \& Davidson, 1986; Gray et al., 1986). Cytochrome $c-553$ of $M$. extorquens also bears no 
Table 1. Physical properties of cytochrome c-553 and cytochrome $c_{L}$

Data for cytochrome $c_{\mathrm{L}}$ are taken from O'Keeffe \& Anthony $(1980 a, b)$ and BeardmoreGray et al. (1982). The proportion of cytochrome $c_{\mathrm{H}}$ in both wild-type bacteria and mutant UV9 was about $70 \%$ of the total soluble cytochrome.

\begin{tabular}{|c|c|c|}
\hline Property & Cytochrome $c-553$ & Cytochrome $c_{\mathrm{L}}$ \\
\hline \multicolumn{3}{|l|}{ Relative proportion in crude extracts } \\
\hline Wild-type & $<5 \%$ & $28 \%$ \\
\hline Mutant UV9 & $30 \%$ & 0 \\
\hline$M_{\mathrm{r}}$ & 23000 & 20900 \\
\hline Haem groups per mol & 1 & 1 \\
\hline Midpoint redox potential ( $\mathrm{pH} 7 \cdot 0$ ) & $+194 \mathrm{mV}$ & $+256 \mathrm{mV}$ \\
\hline \multicolumn{3}{|l|}{ Absorption maxima } \\
\hline Ferrocytochrome & $553 \mathrm{~nm}, 419 \mathrm{~nm}$ & $549 \mathrm{~nm}, 416 \mathrm{~nm}$ \\
\hline Ferricytochrome & $414 \mathrm{~nm}, 695 \mathrm{~nm}$ & $410 \mathrm{~nm}, 695 \mathrm{~nm}$ \\
\hline \multicolumn{3}{|l|}{ Absorption coefficients $\left(\mathrm{mM}^{-1} \mathrm{~cm}^{-1}\right)$} \\
\hline Ferrocytochrome ( $\alpha$ and Soret) & $25 \cdot 3,153$ & 26,163 \\
\hline Ferricytochrome $(695 \mathrm{~nm})$ & 0.58 & $0 \cdot 35$ \\
\hline \multicolumn{3}{|l|}{ Ratio of Soret $/ \alpha$ absorption } \\
\hline Autoreduction at high $\mathrm{pH}$ & None & Fast \\
\hline Electron acceptor for $\mathrm{MDH}$ & No & Yes \\
\hline Autoxidizability & Very slow & Slow \\
\hline Oxidation by membrane oxidase & Very slow & Very slow \\
\hline Reaction with CO (\% binding) & Fast $(100 \%)$ & Slow $(72 \%)$ \\
\hline
\end{tabular}

resemblance to unusual $c$-type cytochromes having no known function that have been isolated from other methylotrophs; these include cytochrome $c-555$ (a small basic protein) from Methylococcus capsulatus (Ambler $e t$ al., 1986), and cytochrome $c^{\prime \prime}$ from Methylophilus methylotrophus, which is exceptional in being a high-spin cytochrome when in the reduced state but low-spin in its oxidized state (Santos \& Turner, 1988).

We thank SERC (UK) and NIH (USA) for financial support.

\section{References}

Ambler, R. P., Dalton, H., Meyer, T. E., Bartsch, R. G. \& Kamen, M. D. (1986). The amino acid sequence of cytochrome $c-555$ from the methane-oxidizing bacterium Methylococcus capsulatus. Biochemical Journal 233, 333-337.

ANTHONY, C. (1982). The Biochemistry of Methylotrophs. London: Academic Press.

Anthony, C. (1986). The bacterial oxidation of methane and methanol. Advances in Microbial Physiology 27, 113-210.

ANTHONY, C. (1988). Quinoproteins and energy transduction. In Bacterial Energy Transduction, pp. 293-316. Edited by C. Anthony. London: Academic Press.

Beardmore-Gray, M., O’Keeffe, D. T. \& Anthony, C. (1982). The autoreducible cytochromes $c$ of the methylotrophs, Methylophilus methylotrophus and Pseudomonas AM1. Biochemical Journal 207, 161-165.

Beardmore-Gray, M., O'KeEfFe, D. T. \& Anthony, C. (1983). The methanol :cytochrome $c$ oxidoreductase activity of methylotrophs. Journal of General Microbiology 129, 923-933.

Cross, A. R. \& ANTHONY, C. (1980). The purification and properties of the soluble cytochromes $c$ of the obligate methylotroph Methylophilus methylotrophus. Biochemical Journal 192, 421-427.
Dijkstra, M., Frank, J., van Wielink, J. E. \& Duine, J. A. (1988) The soluble cytochromes $c$ of methanol-grown Hyphomicrobium X. Biochemical Journal 251, 467-474.

Elliott, E. J. \& ANThONY, C. (1988). The interaction between methanol dehydrogenase and cytochrome $c$ in the acidophilic methylotroph Acetobacter methanolicus. Journal of General Microbiology 134, 369-377.

Froud, S. J. \& ANTHONY, C. (1984). The purification and characterization of the o-type oxidase from Methylophilus methylotrophus, and its reconstitution into a 'methanol oxidase' electron transport chain. Journal of General Microbiology 130, 2201-2212.

FunRHop, J. H. \& SMITH, K. M. (1975). Laboratory methods. In Porphyrins and Metalloporphyrins, pp. 757-869. Edited by K. M. Smith. Amsterdam: Elsevier.

FuKUmori, Y. \& Yamanaka, T. (1987). The methylamine oxidising system of Pseudomonas AM1 reconstituted with purified components. Journal of Biochemistry 101, 441-445.

Fukumori, Y., Nakayama, K \& Yamanaka, T. (1985). Cytochrome $c$ oxidase of Pseudomonas AMI: purification, and molecular and enzymatic properties. Journal of Biochemistry 98, 493-499.

Gershoni, J. M. \& Palade, G. E. (1983). Protein blotting: principles and applications. Analytical Biochemistry 131, 1-15.

Goodhew, C. F., Brown, K. R. \& Pettigrew, G. W. (1986). Haem staining in gels, a useful tool in the study of bacteria $c$-type cytochromes. Biochimica et Biophysica Acta 852, 288-294.

Gray, K. A., KnafF, D. B., Husain, M. \& Davidson, V. L. (1986). Measurement of the oxidation-reduction potentials of amicyanin and $c$-type cytochromes from Paracoccus denitrificans. FEBS Letters 207, 239-242.

Green, P. N. \& Bousefield, I. J. (1982). A taxonomic study of some Gram-negative facultatively methylotrophic bacteria. Journal of General Microbiology 128, 623-638.

Green, P. N., Bousefield, I. J. \& Hood, D. (1988). Three new Methylobacterium species: $M$. rhodesianum sp. nov., $M$. zatmanii sp. nov., and M. fujisawaense sp. nov. International Journal of Systematic Bacteriology 38, 124-127.

Hudson, L. \& Hay, F. C. (1980). Practical Immunology, 2nd edn, pp. 1-3. Oxford: Blackwell Scientific Publications.

Husain, M. \& Davidson, V. L. (1986). Characterization of two inducible periplasmic c-type cytochromes from Paracoccus denitrificans. Journal of Biological Chemistry 261, 8577-8580. 
LAEMMLI, U. K. (1970). Cleavage of structural proteins during the assembly of the head of bacteriophage T4. Nature, London 227, 680-685.

LAWTON, S. A. \& ANTHONY, C. (1985). The role of blue copper proteins in the oxidation of methylamine by an obligate methylotroph. Biochemical Journal 228, 719-726.

Maclennan, D. G., Ousby, J. C., Vasey, R. B. \& Cotton, N. T. (1971). The influence of dissolved oxygen on Pseudomonas AM grown on methanol in continuous culture. Journal of General Microbiology 69, 395-404.

NunN, D. N. \& ANThony, C. (1988). The nucleotide sequence and deduced amino acid sequence of the cytochrome $c_{\mathrm{L}}$ gene of Methylobacterium extorquens AM1: a novel class of c-type cytochromes. Biochemical Journal 256, 673-676.

NUNN, D. N. \& LiDSTROM, M. E. (1986a). Isolation and complementation analysis of 10 methanol oxidation mutant classes and identification of the methanol dehydrogenase structural gene of Methylobacterium sp. strain AMI. Journal of Bacteriology 166, $581-590$.

NunN, D. N. \& Lidstrom, M. E. (1986 $b$ ). Phenotypic characterisation of 10 methanol oxidation mutant classes of Methylobacterium sp. strain AM1. Journal of Bacteriology 166, 591-597.

NunN, D. N., DAY, D. \& ANTHONY, C. (1989). The second subunit of methanol dehydrogenase of Methylobacterium extorquens AM1. Biochemical Journal 260, 857-862.

O'K EEFFE, D. T. \& ANTHONY, C. (1980a) The two cytochromes $c$ in the facultative methylotroph Pseudomonas AM1 Biochemical Journal 192, $411-419$
O'KeEFFE, D. T. \& ANTHONY, C. (1980b) The interaction between methanol dehydrogenase and the autoreducible cytochromes $c$ of the facultative methylotroph Pseudomonas AM1. Biochemical Journal 190, 481-484.

Pettigrew, G. W. \& Moore, G. R. (1987). Cytochrome c: Biological Aspects, p. 13. New York: Springer-Verlag.

SANTOS, H. \& TURNER, D. L. (1988). Characterization and NMR studies of a novel cytochrome $c$ isolated from Methylophilus methylotrophus which shows a redox-linked change of spin state. Biochimica et Biophysica Acta 954, 277-286.

Smith, A., Hill, S. \& AnThony, C. (1988). A haemoprotein is not involved in the control by oxygen of enteric nitrogenase synthesis. Journal of General Microbiology 134, 1499-1507.

Thomas, P. E., Ryan, D. \& Levin, W. (1976). An improved staining procedure for the detection of the peroxidase activity of cytochrome P450 on SDS-polyacrylamide gels. Analytical Biochemistry 75, $168-176$.

Weber, K. \& Osborn, M. (1975). Proteins and sodium dodecyl sulphate; molecular weight determination on polyacrylamide gels and related procedures. In The Proteins, vol. 1, 3rd edn, pp. 179--223. Edited by H. Neurath \& R. L. Hill. London: Academic Press.

WooD, P. M. (1984). Bacterial proteins with CO-binding $b$ - or $c$-type haem functions and absorption spectroscopy. Biochimica et Biophysica Acta 768, 293-317. 